\title{
VENOUS PRESSURE AND POSTURE IN NORMAL YOUNG WOMEN
}

\author{
By JOSEPHINE M. MCINTIRE AND ABBY H. TURNER \\ (From the Physiological Laboratory, Mount Holyoke College, South Hadley)
}

(Received for publication July 23, 1934)

Much work in this laboratory has been concerned with circulatory phenomena in normal young women. Certain studies have given evidence of the very considerable variations shown in adjustments of heart rate and arterial pressures to changes of posture. These have been interpreted from the circulatory standpoint as, at one extreme, a picture of marked success and, at the other extreme, of marked failure in maintaining the erect posture. Since the controlled and adequate return of blood to the heart is a factor of major importance in such circulatory adjustments, measurements of venous pressures in hand and foot with the body in various positions seemed desirable especially when the erect posture is quietly maintained for a considerable period. The number of previous determinations bearing on this point is not large nor do the various observers altogether agree. Mention may be made of von Recklinghausen (1906), Hooker (1911), Barach and Marks (1913), and Carrier and Rehberg (1923). Eyster (1929, p. 33) referred to the work of Barach and Marks as authoritative. It seemed important, however, to study further in young women the varying circulatory success in postural adjustment. We were able to find only one subject with inferior power of adjustment available at this time, but since our basic results differ from those of others they are presented here.

The choice of method was important. It was clear that if determinations were to be repeated frequently during a period lasting often as long as two hours an indirect method was the only one possible. Also we have been skeptical about the use of the direct method of venous puncture for our group since the young college woman as we see her is far from phlegmatic. The possibility of changes in venous pressure due to alterations and fluctuations in muscular tension in a subject outwardly quiet seemed not improbable. Hooker (1911) called attention to the ease with which muscular activity alters venous relations. We also have found that even slight muscular movements markedly alter the readings, for example, in the leg veins of a standing subject under observation by the indirect method.

The indirect method chosen was that of Krogh, Turner, and Landis (1932). The preliminary tests described in that paper were considered sufficient to establish the validity of the method. A few variations in procedure will be noted below. The method chosen is as free as possible from causes which might lead to alterations of pressure other than those due to postural changes and one in which ease of observation is maximal. The whole procedure involves careful attention to detail since the function is so labile. All measurements were made between November, 1932, and April, 1933. The subjects were healthy college students between the ages of 18 and 22 years. Each experiment required about two hours and all disturbing factors such as lack of sleep, minor infections, serious causes of worry, and especially interruptions to the routine of the experiment were avoided. The room temperature was maintained between $21^{\circ}$ and $23^{\circ} \mathrm{C}$., a temperature comfortable for the subject in her relaxed condition, also warm enough to favor easy observation of the skin veins. The aim was to secure a constant and normal flow of blood in the veins chosen. Preliminary work had shown that the uncovered hands and feet of a motionless subject tend to become cool even in a warm room, the amount of blood in the veins becomes markedly reduced and visualization of the flow becomes impossible just when accurate observation is essential. Washing the hands and feet in warm water before beginning the experiment and covering them with soft cotton pads except during the actual time of observation kept them constantly warm even though motionless and thus facilitated observation of the veins. Cross lighting was found best. A loose woolen bathrobe was the only clothing worn by the subject during the experiment, a procedure adopted to avoid all ex- 
ternal pressure upon the venous route between the point of observation and the heart.

A typical experiment was conducted as follows. A celluloid capsule was cemented by collodion over a prominent vein on the back of the hand. A drying time of ten minutes was sufficient. It is necessary that the vein chosen for observation lie over a bone to insure firm support, otherwise the external counterpressure applied in the determination is partially dissipated in the soft tissues which leads to inaccurate readings. In the first series of observations the subject was in a horizontal position on a tilting table. The vein was brought approximately to the level of the right auricle and the hand was then carefully supported to insure steadiness. Pressure on the vein by the capsule itself was avoided by cutting notches in its celluloid margin to fit the special conformation of the vein chosen. A water manometer indicated the degree of pressure which was applied by a thick-walled rubber bulb controlled by a screw clamp. With a certain amount of pressure the vein was seen to collapse, indicating that the external pressure had become about high enough to overcome the internal pressure. Careful observation, however, showed that after this collapse a thin thread of blue was still discernible. A further increase of pressure was found to stop this slender stream in the mid-region of the field under observation. This interruption could be made to come and go by slightly changing the pressure through about $0.5-1.0 \mathrm{~cm}$. water by moving the compressing screw or more readily by pinching the tube. The pressure not at the moment of collapse but at the point of definite interruption to the flow was taken as the true venous pressure. Several determinations were made, separated by a half minute or more. The period of collapse required for each observation was very short, not more than a few seconds for a trained observer.

While the subject was in a reclining position for the application of the capsule on the hand, another capsule was put over a vein in the foot, with the same precaution to secure a bony support. Two or three coats of collodion were found necessary to fasten this capsule firmly to the skin, because of the high pressure needed to collapse the foot veins when the subject was tilted to the erect position. A mercury manometer was substituted for the water type employed for hand pressures; otherwise the apparatus for the veins of hand and foot was the same.

Determinations were made on the veins of both hand and foot at heart level with the subject in a horizontal position. This was always more than a half hour after the subject first reclined.

The subject was then tilted on the board to an angle of $45^{\circ}$, equivalent to a semi-erect position, with the hand kept at heart level, and after a period of fifteen minutes for circulatory adjustment to the new position a series of pressures in the veins of both hand and foot was recorded. The use of the tilting table avoided all muscular effort in changing position.

For a third series of observations the subject was tilted to an almost erect position, an angle of $75^{\circ}$. This angle has been found to be the steepest at which the subject remains passive and feels well supported by the tilting table. If a more erect position is taken the subject begins to feel that her support comes from her own feet, not from the table at her back, and her state is less steady and relaxed. In the $75^{\circ}$ position the column of blood in the veins is influenced by gravity nearly as much as in standing, yet, as shown by metabolism experiments, Newton (1929), the muscular exertion necessary to maintain the erect position is almost entirely eliminated. The increase in oxygen consumption for this tilted position averaged only 5.6 per cent above that for reclining as against an increase of 18.5 per cent for quiet standing. Pressures in the veins of hand and foot were determined again after a fifteen minute period allowed for adjustment.

An important part of the apparatus used on the veins of the foot in the tilted positions was the calibrated counterweighting clamp devised by Krogh, Turner, and Landis. The use of this weight is not necessary on veins of hand or foot at heart level, but at levels considerably below that of the heart the higher pressures then required within the capsule induce cupping of the skin and hence faulty readings unless the counterweighting clamp is applied with sufficient force to keep the skin free from deformation. The calibration previously described was found less reliable for determining the necessary pressure on the clamp than a preliminary observation of the degree of counterweighting required. Skin defor- 
mation varies with the elasticity and tightness of the skin in different subjects and in different positions on the foot. It is also obvious that where venous pressures are high and the veins distended the notches in the rim of the capsule must be cut deep enough to avoid any lowering of the measurement due to cutting off a portion of the venous pressure by the rim of the capsule, especially when counterweighted. It is suggested that certain of the widely varying results obtained by those using the capsule method may be due to the intrinsic difficulties of applying an unnotched capsule.

The observations were recorded in the usual type of protocol. The data were then treated as in Table I, which gives two typical experiments for Subject G. Foot pressures originally taken

\section{TABLE I}

$V$ enous pressures observed in two experiments on Subject $G$. To show changes in pressure with tilting to $45^{\circ}$ and $75^{\circ}$. Hand vein kept at heart level. Hydrostatic factor shows vertical distance between right auricle and foot vein. Experiments indicate degree of uniformity obtained in readings.

\begin{tabular}{c|c|c|c|c}
\hline $\begin{array}{c}\text { Vein } \\
\text { used }\end{array}$ & $\begin{array}{c}\text { Hori- } \\
\text { zontal }\end{array}$ & $\begin{array}{c}45^{\circ} \\
\text { angle }\end{array}$ & $\begin{array}{c}75^{\circ} \\
\text { angle }\end{array}$ & $\begin{array}{c}\text { Hydrostatic } \\
\text { factor }\end{array}$ \\
\hline & $\mathrm{cm} . \mathrm{H}_{2} \mathrm{O}$ & $\mathrm{cm} . \mathrm{H}_{2} \mathrm{O}$ & $\mathrm{cm} . \mathrm{H}_{3} \mathrm{O}$ & $\mathrm{cm} . \mathrm{H}_{2} \mathrm{O}$ \\
\hline
\end{tabular}

Experiment I, January 21, 11:00 a.m.

\begin{tabular}{l|r|r|r|r}
\hline Hand vein & 7.4 & 6.8 & 7.2 & \\
& 6.8 & 7.5 & 6.8 & \\
& 7.0 & 7.2 & 6.7 & \\
\hline Foot vein & 10.1 & 81.0 & 110.7 & $80.5\left(45^{\circ}\right)$ \\
& 10.5 & 83.7 & 113.4 & $110.0\left(75^{\circ}\right)$ \\
& 10.1 & 86.4 & 114.7 & \\
\hline
\end{tabular}

Experiment II, February 23, 11:00 a.m.

\begin{tabular}{l|r|r|r|r}
\hline Hand vein & 7.0 & 6.0 & 6.8 & \\
& 6.5 & 7.5 & 7.2 & \\
\hline Foot vein & 7.0 & 7.0 & 7.2 & \\
\cline { 2 - 4 } & 10.1 & 85.0 & 112.0 & $80.5\left(45^{\circ}\right)$ \\
& 10.5 & 83.7 & 114.7 & $110.0\left(75^{\circ}\right)$ \\
& 11.0 & 87.7 & 118.8 & \\
\hline
\end{tabular}

in $\mathrm{mm} . \mathrm{Hg}$ are converted into $\mathrm{cm}$. water for convenience of comparison. The table includes, in the column headed, "Hydrostatic factor," the figures for the influence of gravity on the circulation in the tilted positions, obtained by measuring the distance in $\mathrm{cm}$. between the foot vein and the level of the right auricle. Similar data for Subject A are shown graphically in Figure 1 where the ordi-

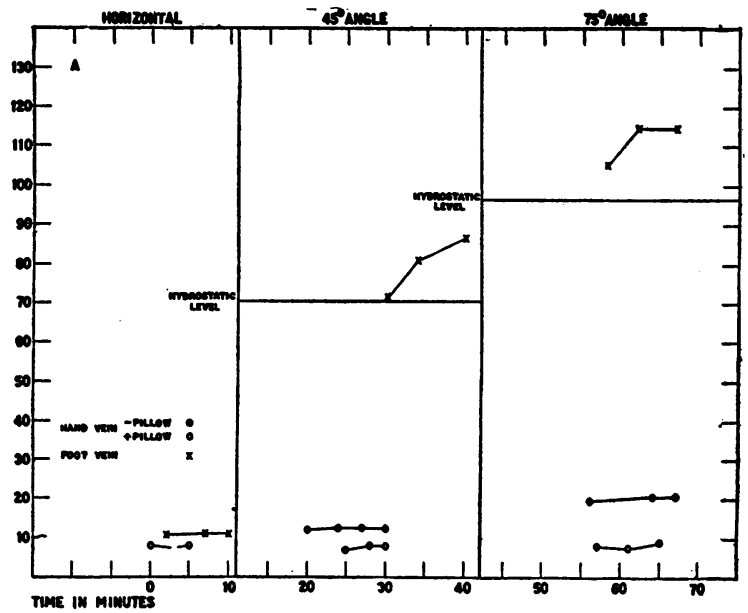

Fig. 1. Venous Pressures Observed in Subject A.

Ordinates, venous pressures in $\mathrm{cm}$. water. Abscissae, time in minutes beginning with the first determination. Preliminary rest period of about $\mathbf{4 0}$ minutes not included.

Two experiments are shown. One, the effect of tilting on pressures in veins of hand and foot, shown by open circles and crosses respectively. The other, the effect of a small pillow under the shoulder on pressure in veins of hand at heart level. Results identical in horizontal position, shown by open circles. For tilted positions: open circles, with pillow; solid dots, without pillow.

nates represent centimeters of water, the abscissae time in minutes. The circles show observations on the vein of the hand, the crosses those on the vein of the foot. The hydrostatic factors are shown for the tilted positions by horizontal lines.

These tables and graphs, which are very similar for the seven subjects, demonstrate that the venous pressure in the large superficial veins of the hands was quite constant in a given subject during the experimental period and with varying posture. This constancy was noted in each of the fourteen experiments chosen as entirely above reproach. Sixteen completed experiments were omitted because of the obvious effect of slight interruptions, delays due to technical difficulties and the like. This constancy of venous pressure in the hand with variations in posture does not support the results of Barach and Marks (1913) who studied arterial and venous pressure in twenty-six human subjects placed in erect and horizontal positions 
on a tilting table. They reported a rise of venous pressure in a vein of the arm when their subjects assumed the erect position, amounting in some cases to as much as $18 \mathrm{~cm}$. water. In connection with their results it is significant that in a series of experiments preliminary to those we have described we also observed an increase of venous pressure when the subject was tilted from horizontal to a $45^{\circ}$ angle and a further increase on tilting to $75^{\circ}$. With the insertion, however, of a small pillow under the shoulder, a manoeuver first adopted for the comfort of the subject, this increase completely disappeared. This increase observed by others, and also at first by ourselves, may arise from the fact that as the subject lying on a flat table is tilted to more erect positions, the line of the clavicle may be altered by the downward pull of the weight of the arm thus lessening

TABLE II

Venous pressures observed in two experiments on Subject $C$. To show change induced by placing a small pillow under shoulder.

\begin{tabular}{c|c|c|c}
\hline Condition & Horizontal & $45^{\circ}$ angle & $7^{\circ}$ angle \\
\hline & $c m . \mathrm{H}_{2} \mathrm{O}$ & $\mathrm{cm} . \mathrm{H}_{2} \mathrm{O}$ & $\mathrm{cm} . \mathrm{H} \mathrm{O}$ \\
\hline
\end{tabular}

Experiment I

\begin{tabular}{l|r|r|r}
\hline Hand vein & 7.0 & 6.5 & 5.0 \\
with pillow & 6.3 & 7.2 & 7.0 \\
under shoulder & 6.2 & 7.0 & 6.5 \\
\hline & & & \\
Hand vein & 7.0 & 10.0 & 18.2 \\
without pillow & 6.8 & 9.2 & 18.7 \\
under shoulder & 6.5 & 11.5 & 19.0 \\
& 6.5 & 12.0 & 19.2 \\
\hline
\end{tabular}

Experiment II

\begin{tabular}{l|l|l|l}
\hline Hand vein & 6.9 & 7.0 & 6.9 \\
with pillow & 6.5 & 6.8 & 7.0 \\
under shoulder & 6.8 & 6.8 & 7.0 \\
& & & 6.2 \\
\hline Hand vein & 7.2 & 10.5 & 18.5 \\
without pillow & 7.0 & 10.7 & 18.6 \\
under shoulder & 6.6 & 10.7 & 18.8 \\
& 6.5 & & 18.8 \\
\hline
\end{tabular}

the space through which the subclavian vein passes between clavicle and first rib. Such a compression of the vein might result in the misleading increase in venous pressure observed in the hand. All experiments were carried on with a small pillow under the shoulder except when this phenomenon was being studied. Table II shows in two experiments for Subject $C$ the characteristic results for pressures in the vein of the hand, with and without the pillow. Similar results are also included in Figure 1 by the black dots for results without the pillow in the tilted positions. The results for the horizontal position are approximately the same with and without the pillow, therefore the small circles satisfy both conditions.

In all experiments in the horizontal position the pressure in the vein of the foot was higher than in the vein of the hand though both were at the level of the heart. The veins of the foot are farther from the heart. Previous work in this laboratory, unpublished, has shown the arterial pressure in the leg to be somewhat higher than that in the arm at heart level; therefore it is not improbable that this higher pressure at the greater distance is required to maintain the gradient of the circulation.

Determinations on veins of the foot were consistent in showing a progressive rise in pressure when the subject was tilted to $45^{\circ}$ and further to $75^{\circ}$. In each position the pressure was practically constant in a given individual after the initial period of fifteen minutes for adjustment. In every subject the venous pressure was somewhat higher than the hydrostatic counter pressure calculated from the difference of levels between the vein observed and the heart. If the blood is to return steadily to the heart in a quiet subject, it is obvious that the venous pressure must at least equal the hydrostatic factor unless the return is dependent upon respiratory or other aids. In Subject $A$, for example, at an angle of $45^{\circ}$ the hydrostatic factor was approximately $70.7 \mathrm{~cm}$. water; the average of three determinations of venous pressure in the vein of the foot was 79.5 $\mathrm{cm}$. When tilted to $75^{\circ}$ the hydrostatic factor was $96.5 \mathrm{~cm}$., the average venous pressure was $111.5 \mathrm{~cm}$. The effect of posture was thus pronounced, and in both tilted positions venous pressure was ample to effect the return of blood to the heart. Such successful adjustments were observed in each of the two experiments on all seven subjects.

These results do not agree with those previously reported by von Recklinghausen (1906), by Hooker (1911), and by Carrier and Rehberg 
(1923). In the veins of the foot in sitting and standing positions von Recklinghausen found that the rise of venous pressure was not sufficient to overcome the opposing hydrostatic factor although it was sufficient to bring the blood to about the entrance to the body cavity. Discrepancies of somewhat lesser magnitudes were found by the other workers. Hooker noted that the quieter the subject the higher the venous pressure in the standing position and that the pressure in a vein of the foot with the subject reclining in a steamer chair might be greater than the hydrostatic factor. Carrier and Rehberg noted that continued maintenance of the standing position caused the venous pressure to approach the values for the hydrostatic factor though always lower. In their work the subject stood on one foot on a stool with the experimental leg hanging relaxed, but fatigue limited the duration of possible observation. If the subject stood on both feet, thus involving muscular effort, the venous pressures in the lower veins were about $20 \mathrm{~cm}$. less. None of these methods made use of a tilting table and it is possible that in spite of intentions to the contrary the blood was helped along by the contraction of the muscles of the leg. The capsules in some studies were not of large size nor were they counterweighted. It is important to note that in our experiments the subjects were entirely relaxed and quiet for a considerable time before as well as during the period of observation, and since these young women felt no trace of dizziness while tilted their circulatory state presumably was reasonably steady.

Though the series is not large enough for statistical treatment, Table III shows the total ranges of venous pressures obtained and the averages for the different positions. The ranges are not wide in comparison with some found in the literature. Some of the very high values reported by others may have been due to a lack of bony support for the vein chosen and a consequent dissipation in the soft tissues of the pressure applied. Also for high pressures the cupping of the skin under the capsule leads to incorrect readings, which were prevented in our work by the counterweighting clamp. There may be a variation in the success with which the end-point is observed for some capsules leave a very limited portion of the vein visible and that none too clearly.
TABLE III

Determinations of venous pressure. Subjects, seven healthy young college women. Indirect method. In $\mathrm{cm}$. water.

\begin{tabular}{|c|c|c|c|}
\hline Postural condition & Average & Total range & $\begin{array}{l}\text { Range of } \\
75 \text { per cent } \\
\text { of readings }\end{array}$ \\
\hline \multicolumn{4}{|c|}{ Hand veins at heart level } \\
\hline $\begin{array}{l}\text { Horizontal. } \ldots \ldots \\
\text { Tilted to } 45^{\circ} \ldots \ldots \\
\text { Tilted to } 75^{\circ} \ldots \ldots\end{array}$ & $\begin{array}{l}7.2 \\
7.9 \\
7.0\end{array}$ & $\begin{array}{ll}6.0- & 8.4 \\
6.0- & 9.5 \\
5.0- & 9.0\end{array}$ & $\begin{array}{ll}6.6- & 8.0 \\
7.0- & 8.7 \\
6.5- & 8.0\end{array}$ \\
\hline \multicolumn{4}{|c|}{ Foot veins } \\
\hline $\begin{array}{l}\text { Horizontal } \ldots \ldots \ldots \\
\text { Tilted to } 45^{\circ} \ldots \ldots \ldots \\
\text { Tilted to } 75^{\circ} \ldots \ldots \ldots\end{array}$ & $\begin{array}{r}10.5 \\
78.4 \\
114.4\end{array}$ & $\begin{array}{r}6.4-12.8 \\
70.2-87.7 \\
102.6-124.2\end{array}$ & $\begin{array}{r}8.9-11.0 \\
75.0-85.0 \\
109.3-120.0\end{array}$ \\
\hline
\end{tabular}

Eyster gives 4 to $6 \mathrm{~cm}$. water as the normal range of venous pressure in the superficial veins of the hand at heart level. Our range is slightly higher, 6 to $8 \mathrm{~cm}$. This difference may easily be due to a clearer field of observation or to the use of a slightly different end-point, the actual interruption of the flow in the vein rather than the first collapse.

\section{Note on pressure in a subject with inferior circulatory adjustments}

While the seven subjects discussed above all showed successful adjustments to the erect posi-

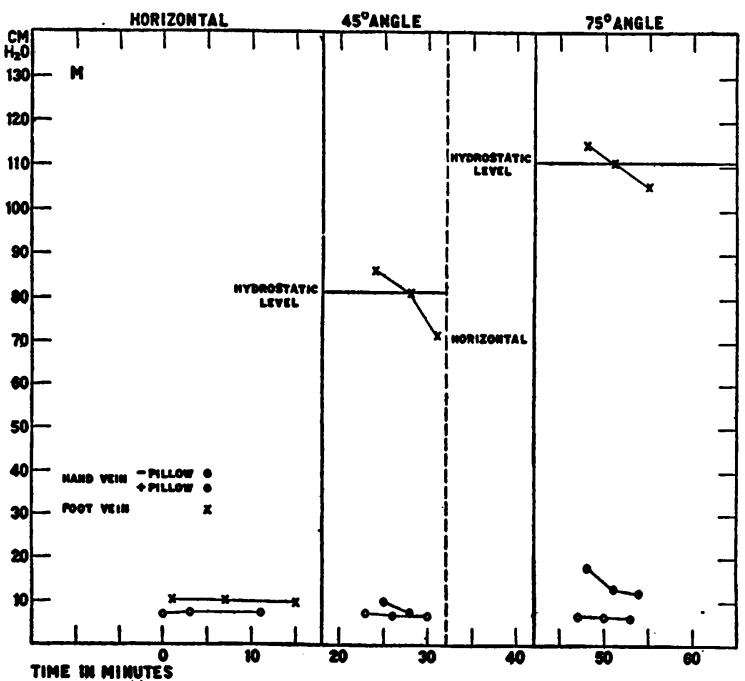

Fig. 2. Subject M, of Infertor Circulatory AdJUSTMENT, Unable Because of Faintness to Endure Tilted Positions Longer than Indicated by Time of Determinations.

Symbols as in Fig. 1. 
tion during the half hour study, an eighth subject repeatedly became dizzy and fainted after six to eight minutes at $75^{\circ}$ or even at $45^{\circ}$. From Figure 2 it is readily seen that the pressures in the vein of her foot when she was tilted to $45^{\circ}$ and $75^{\circ}$ only once equalled the hydrostatic factor, and also that a steady fall in pressure in her foot occurred until dizziness made the erect or semierect position untenable. A slight, possibly not significant, fall is seen in the pressure in her hand at heart level at the same time. Turner, Newton, and Haynes (1930) showed that quiet, healthy, standing young women make extensive circulatory adjustments which are maintained as the quiet position is prolonged although marked variations occurred in different individuals. They observed a distinct and progressive increase in the heart rate, a rise in diastolic pressure, and a lessened pulse pressure when subjects were tilted progressively through a series of angles up to $90^{\circ}$, with all these changes much more marked in subjects who habitually became dizzy when erect and still. There was also evidence of increased volume in the legs due to stagnation of fluid during quiet standing, and evidence for stagnation of blood in the abdominal region. The measurements of venous pressure in our one subject with inferior circulatory adjustment seem to extend the data just summarized for such persons. The low venous pressure in her foot may indicate a failure in the return of blood to the heart. The color of her feet, much more purple than those of the other subjects, also suggested this. It is to be regretted that no other subjects of this type were available.

\section{SUMMARY}

1. Determinations of venous pressure by the indirect method of Krogh, Turner, and Landis have been made on the superficial veins in the hands and feet of seven normal healthy college women while they were subjected to postural changes on a tilting board. The horizontal position and tilted positions at angles of $45^{\circ}$ and $75^{\circ}$ were used.

2. Venous pressure in the superficial veins of the hand at heart level following a preliminary pe- riod for adjustment remained constant for each individual for periods of over an hour, in spite of changes in posture. The effect of the position of the shoulder on the venous pressure in the hand is discussed. The average pressure in the veins of the hand was $7.2 \mathrm{~cm}$. water.

3. The venous pressure in the superficial veins of the foot at heart level, $10.5 \mathrm{~cm}$. water, was somewhat higher than that of the hand in the reclining position.

4. Venous pressure in the veins of the foot increased with change in posture from the horizontal to $45^{\circ}$ and $75^{\circ}$ angles; for each position it remained approximately constant during the experimental period; at both $45^{\circ}$ and $75^{\circ}$ it was somewhat greater than the hydrostatic factor. In healthy subjects who experienced no dizziness in the tilted positions the return of blood therefore seemed assured by venous pressure alone.

5. Readings of venous pressure in one subject with inferior circulatory adjustment when tilted to $75^{\circ}$ showed a pressure in the vein of the foot inadequate to overcome the hydrostatic factor.

\section{BIBLIOGRAPHY}

Barach, J. H., and Marks, W. L., Effect of change of posture-without active muscular exertion-on the arterial and venous pressure. Arch. Int. Med., 1913, 11, 485.

Carrier, E. B., and Rehberg, P. B., Capillary and venous pressure in man. Skandinav. Arch. f. Physiol., 1923, 44, 20.

Eyster, J. A. E., Venous pressure and its clinical applications. Physiol. Rev., 1926, 6, 281.

Eyster, J. A. E., Clinical Aspects of Venous Pressure. Macmillan, New York, 1929.

Hooker, D. R., The effect of exercise upon the venous blood pressure. Am. J. Physiol., 1911, 28, 235.

Krogh, A., Turner, A. H., and Landis, E. M., A celluloid capsule for measuring venous pressures. J. Clin. Invest., $1932,11,357$.

Newton, M. I., The effect of posture on circulation and metabolism. Unpublished results. 1929.

von Recklinghausen, $H$., Unblutige Blutdruckmessung. III. Messung des Blutdrucks in den kleinen Arterien Venen und Kapillaren des Menschen und beim Tier. Arch. f. exper. Path. u. Pharmakol., 1906, 55, 463.

Turner, A. H., Newton, M. I., and Haynes, F. W., The circulatory reaction to gravity in healthy young women. Am. J. Physiol., 1930, 94, 507. 